Review

\title{
Modelling Catalyst Surfaces Using DFT Cluster Calculations
}

\section{Izabela Czekaj *, Jörg Wambach and Oliver Kröcher}

Energy Department, Paul Scherrer Institute, 5232 Villigen PSI, Switzerland;

E-Mails: joerg.wambach@psi.ch (J.W.); oliver.kroecher@psi.ch (O.K.)

* Author to whom correspondence should be addressed; E-Mail: izabela.czekaj@psi.ch (I.C.);

Tel.: +41-56-301-4464; Fax: +41-56-301-2199.

Received: 5 August 2009; in revised form: 7 September 2009 / Accepted: 15 September 2009 / Published: 30 September 2009

\begin{abstract}
We review our recent theoretical DFT cluster studies of a variety of industrially relevant catalysts such as $\mathrm{TiO}_{2}, \gamma-\mathrm{Al}_{2} \mathrm{O}_{3}, \mathrm{~V}_{2} \mathrm{O}_{5}-\mathrm{WO}_{3}-\mathrm{TiO}_{2}$ and $\mathrm{Ni} / \mathrm{Al}_{2} \mathrm{O}_{3}$. Aspects of the metal oxide surface structure and the stability and structure of metal clusters on the support are discussed as well as the reactivity of surfaces, including their behaviour upon poisoning. It is exemplarily demonstrated how such theoretical considerations can be combined with DRIFT and XPS results from experimental studies.
\end{abstract}

Keywords: DFT; cluster model; in situ DRIFTS; in situ XPS; metal-support interactions; reaction mechanism

\section{Introduction}

One of the long-term targets of research in heterogeneous catalysis is to gain an understanding of the processes of interest on a molecular level, in order to discover general catalysis principles and/or to develop better catalysts based on rational design. With this goal we started a few years ago to investigate: (i) detailed surface-reaction mechanisms, and (ii), surface modifications during catalytic reactions (processes like oxidation, reduction, clustering, deactivation, and so on). For a given reaction, we study both commercial catalysts and home-made model catalysts with identical or at least similar composition, and follow the surface processes and modifications applying a complimentary combination of surface science analytical techniques (e.g., XPS, DRIFTS) under in situ or quasi in situ conditions [1]. However, a comprehensive view of the processes occurring on the catalyst surface can 
only be obtained by combining these results with modelling of the reaction mechanism using ab initio DFT methods [2,3]. In our present studies we use a cluster model, which is often applied in modelling of catalytically active centres, for geometrical representation of the surfaces [4,5].

Our activities are part of the projects of the General Energy Research Department of the Paul Scherrer Institute (PSI). Within the broad research portfolio covered at PSI, we have focused our interest on a sustainable energy supply for future mobility by catalytic conversion of renewable primary fuels (e.g., biomass) to secondary fuels (hydrogen, methane) via synthesis gas $\left(\mathrm{CO}+\mathrm{x} \mathrm{H}_{2}\right)$ and on the urea-SCR processes for the removal of $\mathrm{NO}_{\mathrm{x}}$ from diesel vehicles. One example to be shown will illustrate how the production of methane from reformer gas induces surface modifications on a $\mathrm{Ni} / \mathrm{Al}_{2} \mathrm{O}_{3}$ catalyst [1]. The influence of biomass derived synthesis gas on the surface properties of the catalyst and on its reactivity under methanation conditions was investigated by combined High Pressure Reaction Cell (HPC)-XPS experiments. Recently, theoretical studies were performed to understand the molecular structure of the $\mathrm{Ni} / \mathrm{Al}_{2} \mathrm{O}_{3}$ catalyst and why nickel particles detach from the surface during methanation.

Another example which we will discuss is the investigation of catalysts for the urea-SCR process. A variety of different catalysts can be used for SCR processes, such as $\mathrm{TiO}_{2}$ or $\mathrm{Al}_{2} \mathrm{O}_{3}$ for the urea decomposition and more complex systems, such as $\mathrm{V}_{2} \mathrm{O}_{5} / \mathrm{WO}_{3}-\mathrm{TiO}_{2}$ or metal-exchanged zeolites, for the actual SCR reaction. We will exemplarily show the differences in the reaction mechanisms of the hydrolysis of isocyanic acid (HNCO) on anatase $\mathrm{TiO}_{2}(101)$ and $\gamma-\mathrm{Al}_{2} \mathrm{O}_{3}[6-8]$, which were revealed combining ab-initio DFT calculations using a cluster model with in situ DRIFTS investigations. Furthermore, a characterization study on the deactivation of $\mathrm{V}_{2} \mathrm{O}_{5} / \mathrm{WO}_{3}-\mathrm{TiO}_{2}$ SCR catalysts [9] by alkali metals originating from additives or impurities from fuels and lubrication oils has been performed. Combination of theoretical calculations (excited state of core electrons) and experimental XPS studies has been used for describing the role of alkali metals in blocking the catalytically active sites.

\section{Computational Details}

The calculations described in this paper were performed with clusters models. We used density functional theory (DFT) methods (StoBe program code [10]) together with the non-local generalized gradient corrected functionals (RPBE) according to Perdew, Burke, and Ernzerhof [11,12]. All KohnSham orbitals are represented by linear combinations of atomic orbitals (LCAOs) using extended basis sets of contracted Gaussians from atom optimizations [13,14]. Detailed analyses of the electronic structure in the clusters are carried out using Mulliken populations [15] and Mayer bond order indices $[16,17]$. The calculations of the vibrational frequencies were performed with harmonic approximations as well as an anharmonicity fit in the Morse potential function, as implemented in the StoBe code [18]. Full geometry optimization of the adsorbed species and the active centers on the clusters were performed. Atoms were allowed to move in the 3-dimentional space without constraints until equilibrium has been reached. Double zeta valence polarization (DZVP) type was used for the orbital basis sets, which we found to be sufficiently accurate (see [7]). Theoretical vibrational spectra were obtained by convolution of the vibrational spectra of the individual adsorbates, applying Gaussian lineshapes. The frequencies are reported as obtained from the calculations, without scaling. 
In our studies the catalyst surfaces were modelled by clusters of different size and geometry, which were saturated by hydrogen atoms with $\mathrm{R}_{\mathrm{OH}}=0.97 \AA$. For modelling the $\mathrm{TiO}_{2}(101)$ surface, $\mathrm{Ti}_{2} \mathrm{O}_{9} \mathrm{H}_{10}$, $\mathrm{Ti}_{8} \mathrm{O}_{28} \mathrm{H}_{24}, \mathrm{Ti}_{13} \mathrm{O}_{43} \mathrm{H}_{34}$ and $\mathrm{Ti}_{15} \mathrm{O}_{50} \mathrm{H}_{40}$ were selected as clusters [6], among which the $\mathrm{Ti}_{8} \mathrm{O}_{28} \mathrm{H}_{24}$ cluster proved to be best suited for further reaction studies. In case of the $\gamma-\mathrm{Al}_{2} \mathrm{O}_{3}(100)$ surface, $\mathrm{Al}_{11} \mathrm{O}_{30} \mathrm{H}_{27}$, $\mathrm{Al}_{15} \mathrm{O}_{40} \mathrm{H}_{35}$ and $\mathrm{Al}_{25} \mathrm{O}_{58} \mathrm{H}_{41}$ clusters were studied, from which $\mathrm{Al}_{11} \mathrm{O}_{30} \mathrm{H}_{27}$ was finally selected for adsorption and $\mathrm{Al}_{15} \mathrm{O}_{40} \mathrm{H}_{35}$ for $\mathrm{Ni}$ cluster deposition study. Three different clusters of nickel were deposited at $\gamma-\mathrm{Al}_{2} \mathrm{O}_{3}$ surface $\left(\mathrm{Ni}_{2}, \mathrm{Ni}_{7}, \mathrm{Ni}_{9}\right)[2,3]$. In case of $\mathrm{V}_{2} \mathrm{O}_{5}(010)$ surface, the $\mathrm{V}_{6} \mathrm{O}_{20} \mathrm{H}_{10}$ cluster has been used for surface representation [9].

\section{Results and Discussion}

\subsection{Modelling of Metal-Support Interactions}

Our first example for the combination of DFT calculation with experimental studies of heterogeneous catalysts deals with the production of methane from synthesis gas. The effect of the composition of synthesis gas, starting with pure $\mathrm{CO}+\mathrm{H}_{2}$ and approaching in stepwise fashion the composition as delivered from an existing wood gasifier, on the surface properties of a commercial $\mathrm{Ni} / \mathrm{Al}_{2} \mathrm{O}_{3}$ catalyst and on its activity under methanation conditions was studied on an atomic level by quasi in-situ X-ray photoelectron spectroscopy (XPS) [1]. One of the conclusions was that the stability of the $\mathrm{Ni}$ particles on the $\gamma-\mathrm{Al}_{2} \mathrm{O}_{3}$ support can be influenced by cluster growth phenomena, which influence both size and distribution of the metal particles.

In order to shed light on the involved metal-support interactions, a theoretical study has been performed [2,3]. It was shown that the deposition of a very low number $\left(\Theta_{\mathrm{Ni}}<0.4 \mathrm{~mL}\right)$ of metal atoms on $\gamma-\mathrm{Al}_{2} \mathrm{O}_{3}$ only influences the local surface structure, in particular the neighbouring centres of $\mathrm{Ni}$, such as: $\mathrm{Al}(4), \mathrm{Al}(5), \mathrm{O}(3)$ and $\mathrm{O}^{\prime}(3)$ (see previous paper [3]). The stabilization energy of deposited nickel particles on $\mathrm{Al}_{15} \mathrm{O}_{40} \mathrm{H}_{35}$ cluster was calculated as difference between the total energy of the metal deposited on the $\gamma-\mathrm{Al}_{2} \mathrm{O}_{3}$ surface and sum of the total energies of pure $\mathrm{Al}_{15} \mathrm{O}_{40} \mathrm{H}_{35}$ and the metal atoms, respectively. In all cases, the first layer of nickel on $\mathrm{Al}_{2} \mathrm{O}_{3}(100)$ deposits in positions closer to octahedral $\mathrm{O}(3)$ centres (see Table 1) with different stabilization energies per $\mathrm{Ni}$ atom (for $\mathrm{Ni}_{2}$ : $-0.82 \mathrm{eV}$, for $\mathrm{Ni}_{7}$ : $-0.90 \mathrm{eV}$ and for $\mathrm{Ni}_{9}:-0.71 \mathrm{eV}$ ). The calculated stabilization energies for the different Ni clusters are comparable with published energies obtained for the adsorption of different metals, mainly $\mathrm{Pd}$, on $\gamma-\mathrm{Al}_{2} \mathrm{O}_{3}[19,20]$. Being strongly bound to $\mathrm{O}(3)$ centres, the deposited nickel influences the electronic structure of the $\gamma-\mathrm{Al}_{2} \mathrm{O}_{3}$, too. The largest investigated nickel cluster $\left(\mathrm{Ni}_{9}\right)$ creates many interesting structures at the support surface. Figure 1a shows only the interface atoms (green spheres) of the $\mathrm{Ni}_{9}$ cluster after relaxation. The interfacing $\mathrm{Ni}$ atoms correspond to a coverage $\theta_{\mathrm{Ni}} \sim 0.40 \mathrm{~mL}$. The figure was created by multiplying the calculated $\mathrm{Ni} / \mathrm{Al}_{2} \mathrm{O}_{3}$ cluster in $\mathrm{x}$ and $\mathrm{y}$ direction (see Figure1b). Black dots symbolize the mismatch of an "ideal" Ni(100) monolayer with the $\gamma-\mathrm{Al}_{2} \mathrm{O}_{3}$ surface. Strong vertical and lateral re-arrangements of the interface $\mathrm{Ni}$ atoms in the $\mathrm{Ni}_{9}$ clusters with respect to the position on the $\mathrm{Ni}(100)$ surface are indicated by our DFT results. Part of the interfacing nickel atoms $\left(\mathrm{Ni}^{1 \text { st }}\right)$ seem to prefer the "valley regions" between the $\mathrm{AlO}_{5}$ rows, close to the $\mathrm{O}(3)$ centres. These $\mathrm{O}(3)$ centres are mostly influenced creating strong bonds with the first (interfacing) nickel atoms. 
Table 1. Results obtained by DFT calculations summarising atomic charges (eV), distances $(\AA)$ and bond orders (Mayer bond analysis) of (a) the pure $\mathrm{Al}_{15} \mathrm{O}_{40} \mathrm{H}_{35}$ cluster, (b) the $\mathrm{Ni}_{9} / \mathrm{Al}_{2} \mathrm{O}_{3}$ cluster.

\begin{tabular}{|l|l|l|}
\hline Cluster: & $\mathrm{Al}_{15} \mathrm{O}_{40} \mathrm{H}_{35}$ & $\mathrm{Ni}_{9} / \mathrm{Al}_{15} \mathrm{O}_{40} \mathrm{H}_{35}$ \\
\hline Centre & Charge $[\mathbf{e V}]$ & \\
\hline $\mathrm{Al}(4)$ & +1.58 & +2.16 \\
\hline $\mathrm{Al}(5) / \mathrm{Al}(6)$ & $+0.99 /+1.11$ & $+1.01 /+1.15$ \\
\hline $\mathrm{O}(3) / \mathrm{O}^{\prime}(3)$ & $-0.68 /-0.75$ & $-0.92 /-0.89$ \\
\hline $\mathrm{Ni}^{1 \text { st }}$ & - & +0.35 \\
\hline Bond & Bond Order & \\
\hline $\mathrm{O}(3)-\mathrm{Al}(5)$ & $0.73 / 0.66$ & $0.66 / 0.51$ \\
$\mathrm{O}(3)-\mathrm{Al}(6)$ & 0.62 & 0.53 \\
$\mathrm{O}(3)-\mathrm{Ni}$ & - & $0.15(2.09 \AA)$ \\
\hline $\mathrm{O}^{\prime}(3)-\mathrm{Al}(5)$ & $0.66 / 0.66$ & $0.57 / 0.55$ \\
$\mathrm{O}^{\prime}(3)-\mathrm{Al}(4)$ & 0.63 & 0.38 \\
$\mathrm{O}^{\prime}(3)-\mathrm{Ni}$ & - & $0.004(3.10 \AA)$ \\
\hline
\end{tabular}

Figure 1. $\mathrm{Ni} / \mathrm{Al}_{2} \mathrm{O}_{3}$ cluster; colour code: (Ni: grey spheres; Oxygen: red spheres; Hydrogen: white spheres). (a) Topography (top view) of the interfacing Ni atoms (green spheres) for the relaxed $\mathrm{Ni}_{9}$ cluster on an $\mathrm{Al}_{15} \mathrm{O}_{40} \mathrm{H}_{35}$ cluster; all $\mathrm{Ni}$ interface atoms included $\left(\theta_{\mathrm{Ni} \text {,interface }} 0.4 \mathrm{~mL}\right)$. Black dots symbolize the position of $\mathrm{Ni}$ atoms of an ideal $\mathrm{Ni}(100)$ monolayer; (b) side view onto a relaxed entire $\mathrm{Ni}_{9}$ cluster $\left(\theta_{\mathrm{Ni}} \sim 0.4 \mathrm{~mL}\right)$ bound on an $\mathrm{Al}_{15} \mathrm{O}_{40} \mathrm{H}_{35}$ cluster.

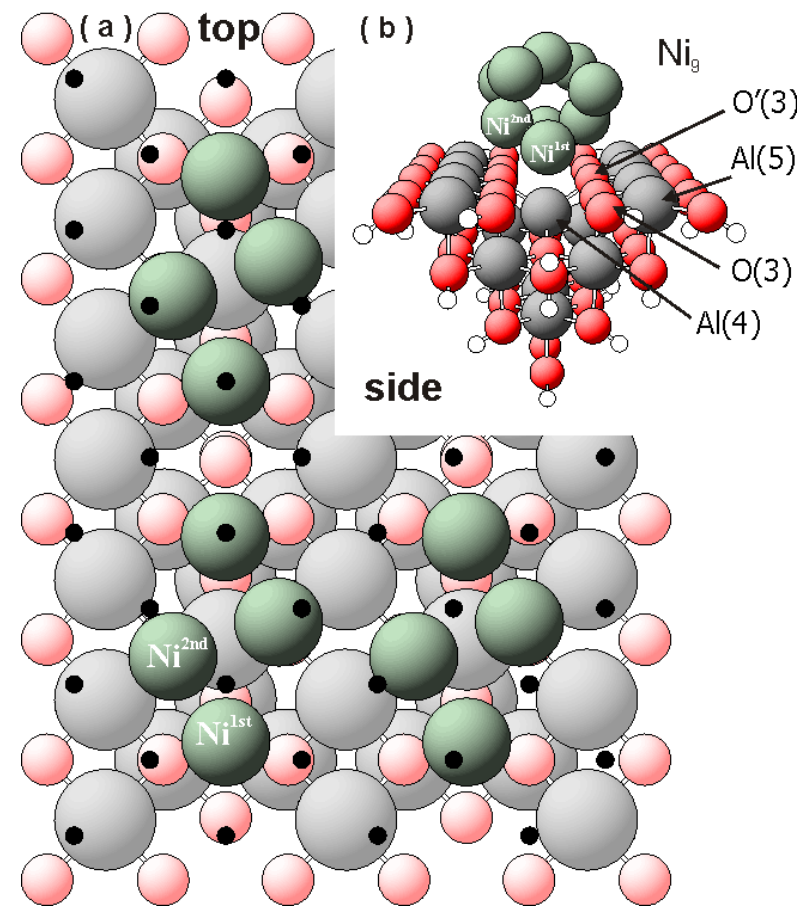

This finding is in good accordance with our experimental results (see Figure 2), where we observed the existence of electronically strongly altered $\mathrm{Ni}$ adsorbed on $\gamma-\mathrm{Al}_{2} \mathrm{O}_{3}$ in the first stage of the deposition. Our experimental studies suggest that $\mathrm{Ni}$ does not form clusters immediately, but one-dimensional (or possibly small two-dimensional) agglomerates, initially. This seems to be valid 
for nickel coverages up to $\Theta_{\mathrm{Ni}} 0.5 \mathrm{~mL}$. Further growth of these initial agglomerates following a layer-by-layer growth mode (see the red line) was not found. Our data clearly show a deviation from the expected behaviour exhibiting smaller $\mathrm{Ni} 2 \mathrm{p}_{3 / 2} / \mathrm{Al} 2 \mathrm{p}$ values. This indicates that in the second stage three-dimensional $\mathrm{Ni}$ clusters are formed on the surface. We conclude that Ni deposition on $\gamma-\mathrm{Al}_{2} \mathrm{O}_{3}$ follows a "modified" Stranski-Krastanov growth mode under the applied experimental conditions, which is in accordance with the findings of Jacobs et al. [21].

Figure 2. Changes of $\mathrm{Ni} 2 \mathrm{p}_{3 / 2} / \mathrm{Al} 2 \mathrm{p}$ ratio during deposition of nickel onto the $\mathrm{Al}_{2} \mathrm{O}_{3}$ support. The red line corresponds to the theoretical expectation of development of the Ni $2 p_{3 / 2} / A 12 p$ ratio for a layer-by-layer growth. The dashed line indicates the proposed start of the $3 \mathrm{D}$ cluster growth.

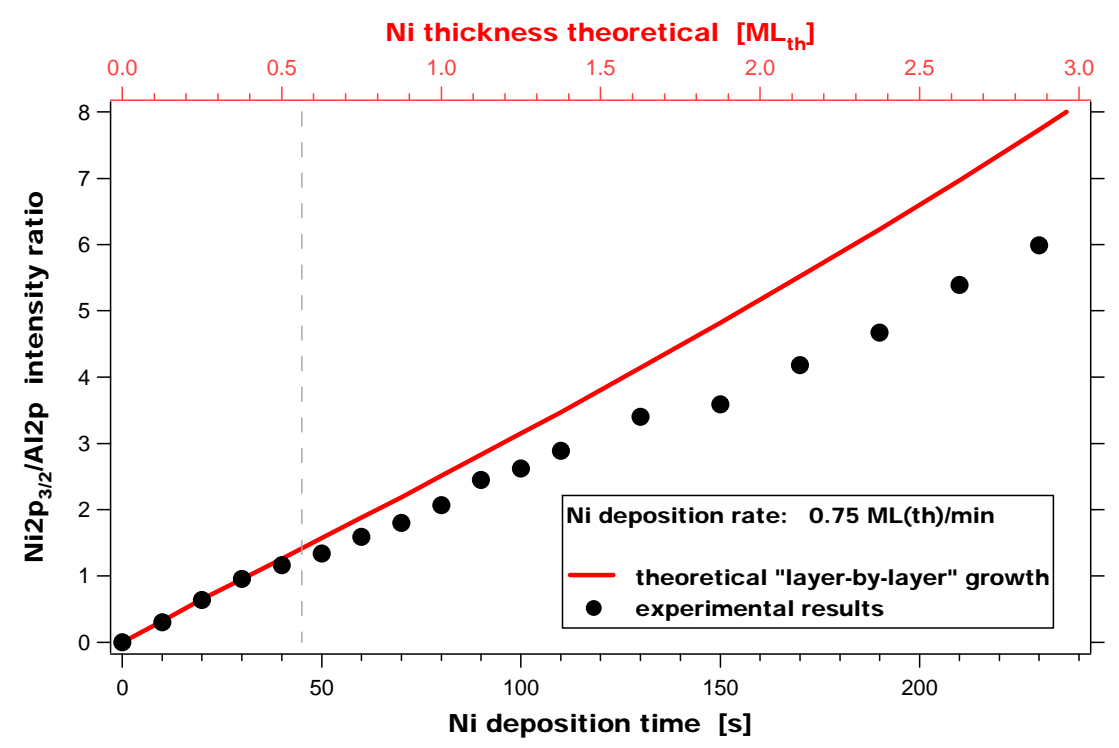

Summarizing, we conclude that nickel is stabilized on the $\gamma-\mathrm{Al}_{2} \mathrm{O}_{3}$ surface influencing the electronic properties of the newly formed surface. Our DFT data suggest that at low coverages $(\leq 0.2 \mathrm{~mL}) \mathrm{Ni}$ prefers being localized in $\mathrm{AlO}_{4}$ tetrahedra between rows of $\mathrm{AlO}_{5}$. The DFT results are in good agreement with the experimentally obtained results from the initial stage of Ni deposition, where the formation of a "partial $\mathrm{Ni}$ monolayer" is suggested. Further $\mathrm{Ni}$ deposition first leads to three-dimensional agglomerates, which are finally transferred to $\mathrm{Ni}$ clusters on the surface by continued Ni deposition, as was derived from the slow approach of the XPS binding energy to the value of bulk $\mathrm{Ni}$. For $\mathrm{Ni}_{7}$ and $\mathrm{Ni}_{9}$ clusters, the initially deposited $\mathrm{Ni}$ atoms, which represent the

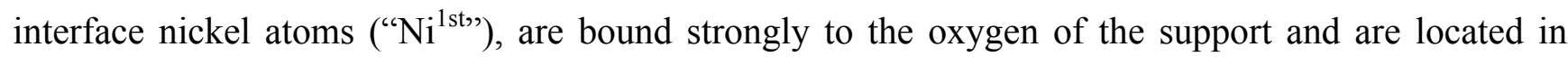
positions closer to $\mathrm{O}(3)$ centres as well as between rows of $\mathrm{AlO}_{5}$ with adsorption energy, which varies with the size of the cluster. The astonishingly good agreement between the experimental data and our theoretical studies shows the good accuracy of cluster model calculations for investigating metal-support structures. 


\subsection{Water Adsorption on Metal Oxide Surfaces: $\mathrm{TiO}_{2}$ and $\mathrm{Al}_{2} \mathrm{O}_{3}$}

The effects of water adsorption on different catalysts are of high importance, because water is present in many processes, such as the methanation of syngas or the SCR process with humid exhaust gas. $\mathrm{TiO}_{2}$ and $\mathrm{Al}_{2} \mathrm{O}_{3}$ are interesting materials for both processes, which are discussed as urea decomposition catalysts or as support for methanation catalysts.

Molecular and dissociative adsorption of water is possible on both substrates [22-28]. Figure 3 shows the corresponding geometric and the electronic structures of the surfaces for both types of catalysts. The calculations of the water adsorption showed that the $\mathrm{M}(5)$ centres $(\mathrm{M}=\mathrm{Ti}, \mathrm{Al})$ are involved on the $\mathrm{TiO}_{2}$ as well as the $\mathrm{Al}_{2} \mathrm{O}_{3}$ surface. Concerning dissociative adsorption, one hydrogen atom of the water molecule is transferred to and stabilized at a surface oxygen centre. In case of $\mathrm{TiO}_{2}$,

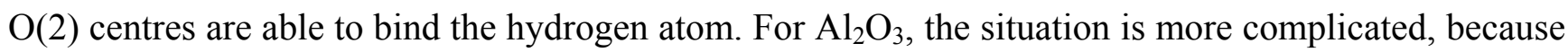
at the surface exist two types of 3-fold coordinated oxygen centres, $\mathrm{O}(3)$ and $\mathrm{O}^{\prime}(3)$. The $\mathrm{O}(3)$ centres are bound to $\mathrm{Al}(5)$ and $\mathrm{Al}(6)$ centres, while $\mathrm{O}^{\prime}(3)$ are linked to $\mathrm{Al}(5)$ and $\mathrm{Al}(4)$ centres. As visible in Table 1, the oxygen in $\mathrm{O}(3)$ has a lower charge and it is stronger bound than in case of the O'(3) centres. Our results show that hydrogen prefers to be adsorbed on the $\mathrm{O}(3)$ oxygen sides. In case of hydrogen bound to O'(3) centres, our optimisation results indicate an immediate hydrogen transfer to the $\mathrm{O}(3)$ centres. Water can be stabilized molecularly at a $\mathrm{M}(5)$ centre with an adsorption energy of $-1.19 \mathrm{eV}$ and $-1.52 \mathrm{eV}$ for $\mathrm{TiO}_{2}$ and $\mathrm{Al}_{2} \mathrm{O}_{3}$, respectively, whereas water adsorbs dissociatively with an adsorption energy of $\mathrm{E}_{\mathrm{ad}}=-0.84 \mathrm{eV}$ and $-1.06 \mathrm{eV}$ on both materials at a $\mathrm{M}(5)$ centers.

Figure 3. Geometric structure of water at $\mathrm{TiO}_{2}$ and $\mathrm{Al}_{2} \mathrm{O}_{3}$. Colour code: (oxygen: red, titanium-yellow, aluminium-dark gray, hydrogen-light gray).

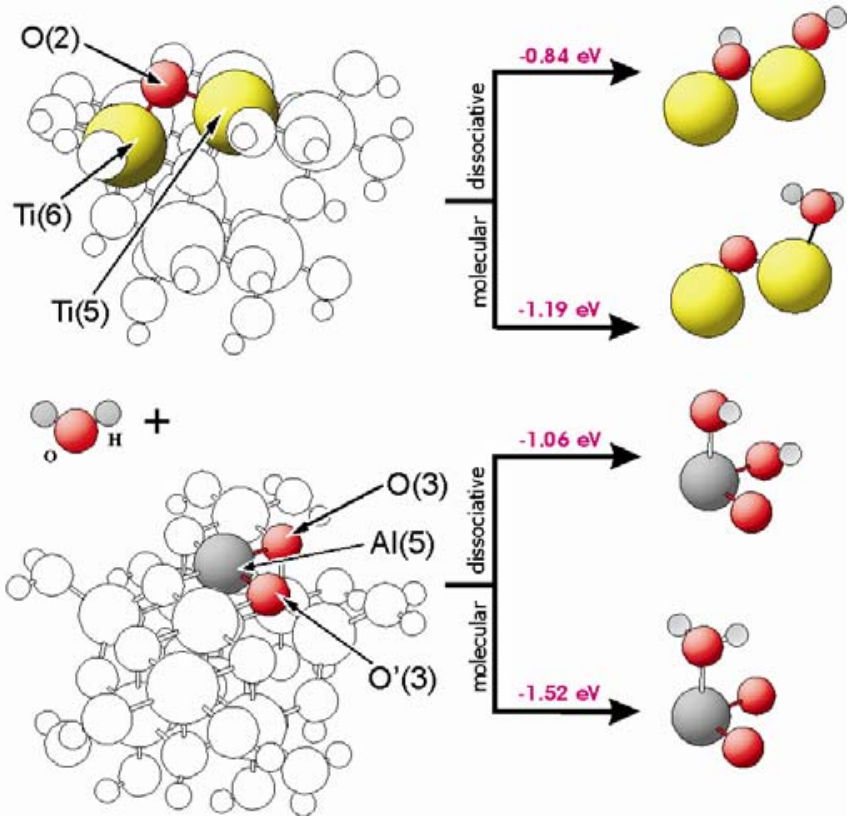

Table 2 shows the calculated characteristic vibrational frequencies of water being bound to $\mathrm{TiO}_{2}$ and $\mathrm{Al}_{2} \mathrm{O}_{3}$. Although molecular adsorption of water should be energetically even more favoured, 
dissociative adsorption of water is observed over the whole temperature range and even at low temperatures $\left(50{ }^{\circ} \mathrm{C} / 323 \mathrm{~K}\right)[29]$.

Table 2. Theoretical DRIFT spectra-characteristic vibrations of water at $\mathrm{TiO}_{2}$ and $\mathrm{Al}_{2} \mathrm{O}_{3}$.

Data taken from our DFT calculations.

\begin{tabular}{|c|c|c|c|c|}
\hline $\mathbf{T i O}_{\mathbf{2}}$ & $\mathbf{H}_{\mathbf{2}} \mathbf{O}_{\text {mol }}$ & $\mathbf{H}_{\mathbf{2}} \mathbf{O}_{\text {diss }}$ & $\mathbf{H}_{\mathbf{2}} \mathbf{O}_{\text {mol }}$ & $\mathbf{H}_{\mathbf{2}} \mathbf{O}_{\text {diss }}$ \\
\hline Vibrational Mode & \multicolumn{2}{|c|}{$\mathbf{T i O}_{\mathbf{2}}$} & \multicolumn{2}{c|}{$\mathbf{A l}_{\mathbf{2}} \mathbf{O}_{\mathbf{3}}$} \\
\hline$\delta(\mathrm{H}-\mathrm{O}-\mathrm{H})$ & 1,646 & - & 1,595 & - \\
\hline$v(\mathrm{O}(1) \mathrm{H})$ & 3,591 & 3,623 & 3,359 & 3,338 \\
\hline$v(\mathrm{O}(2) \mathrm{H})$ & 3,744 & 3,654 & 3,692 & 3,664 \\
\hline
\end{tabular}

Figure 4 shows a comparison between simulated and measured IR spectra of water adsorbed on $\mathrm{TiO}_{2}$. Only bands deriving from water adsorption are visible in case of the theoretical spectrum. The band at $1,629 \mathrm{~cm}^{-1}$ found in the experimental DRIFT spectrum at $50{ }^{\circ} \mathrm{C}$ is in good agreement with the vibrational frequency of $1,646 \mathrm{~cm}^{-1}[\delta(\mathrm{H}-\mathrm{O}-\mathrm{H})]$ obtained from DFT calculations for molecularly adsorbed water with respect to the used approximations. There is also a fair match between the experimental band at $3,691 \mathrm{~cm}^{-1}$ in the DRIFT spectrum and the theoretical band at $3,744 \mathrm{~cm}^{-1}$ $[v(\mathrm{O}(2) \mathrm{H})]$ in the "DFT" spectrum. On first view, it seems that the experimental band at $3,630 \mathrm{~cm}^{-1}$ is also caused by molecularly adsorbed water. However, we believe that this band can rather be attributed to dissociatively adsorbed water, which was found to have a theoretical frequency of $3,623 \mathrm{~cm}^{-1}$ $[v(\mathrm{O}(1) \mathrm{H})]$. The experimental bands at $3,670 / 3,667 \mathrm{~cm}^{-1}$ in the DRIFT spectra at $50{ }^{\circ} \mathrm{C}$ and $450{ }^{\circ} \mathrm{C}$, respectively, are also compatible with dissociatively adsorbed water with a calculated band at $3,654 \mathrm{~cm}^{-1}\left[v\left(\mathrm{O}_{\mathrm{s}}(2) \mathrm{H}\right)\right]$ (see green dotted line in Figure 4). The stretching vibration at $3,623 \mathrm{~cm}^{-1}$ $[v(\mathrm{O}(1) \mathrm{H})]$ is connected with hydroxyl groups adsorbed at the $\mathrm{Ti}(5)$ centres and the stretching vibration at 3,654 $\mathrm{cm}^{-1}\left[v\left(\mathrm{O}_{\mathrm{s}}(2) \mathrm{H}\right)\right]$ results from hydroxyl groups formed with the $\mathrm{O}_{\mathrm{s}}(2)$ surface oxygen atoms $\left[\mathrm{O}_{\mathrm{s}}(2)-\mathrm{H}\right]$. However, a detailed analysis of the experimental spectra at $450{ }^{\circ} \mathrm{C}$ (see Figure $4 \mathrm{c}$ ) shows that the absorbance of the $v[\mathrm{O}(1) \mathrm{H}]$ vibration is much weaker than that of $v\left[\mathrm{O}_{\mathrm{s}}(2)-\mathrm{H}\right]$ one, which suggests a higher population of $\mathrm{O}_{\mathrm{s}}(2)-\mathrm{H}$ sites (with theoretical frequency $3,654 \mathrm{~cm}^{-1}$, see Figure 4d). A lower population of hydroxyl groups at Ti(5) centres is a very important feature for the adsorption of HNCO on these sites as a prerequisite for the hydrolysis reaction. It should be noted that the DRIFT spectrum of $\mathrm{TiO}_{2}$ at $50{ }^{\circ} \mathrm{C}$ shows also a broad band in the range $2,500-3,740 \mathrm{~cm}^{-1}$, which is typical for the presence of liquid water due to the formation of hydrogen bridging bonds [30].

The comparison of the calculated vibration frequencies with the DRIFT experiments suggests that at lower temperatures $\left(50{ }^{\circ} \mathrm{C}\right.$ ) both molecular (bands at 1,629 and 3,691 $\mathrm{cm}^{-1}$ ) and dissociative (bands at 3,630 and 3,670 $\mathrm{cm}^{-1}$ ) adsorption of water occurs with higher amounts of molecularly adsorbed water. At higher temperatures $\left(450{ }^{\circ} \mathrm{C}\right.$ ) mainly dissociative adsorption (bands at 3,667 and 3,724 $\mathrm{cm}^{-1}$ ) was observed (see Figures $4 \mathrm{c}$ and d).

The combination of theoretical and experimental vibrational spectroscopic studies allows the identification of surface species and how they are adsorbed on the surface and show in detail which species remain on the surface even after drying of the catalyst. We have demonstrated such a comparison for water adsorption, which always occur under humid process conditions on 
heterogeneous catalysts, but it is also useful for studying other adsorbates, for example isocyanic acid, which is hydrolyzed over $\mathrm{TiO}_{2}$ in the urea-SCR process.

Figure 4. Theoretical IR spectra and experimental DRIFT spectra of the adsorption reaction experiments dosing $\sim 200 \mathrm{ppm} \mathrm{H}_{2} \mathrm{O}$ onto fresh $\mathrm{TiO}_{2}$ at $\mathrm{T}=50{ }^{\circ} \mathrm{C}$ and $450{ }^{\circ} \mathrm{C}$. (a) DRIFT spectrum at $50{ }^{\circ} \mathrm{C}$. (b) Theoretical IR spectrum at $50{ }^{\circ} \mathrm{C}$. (c) DRIFT spectrum at $450{ }^{\circ} \mathrm{C}$. (d) Theoretical IR spectrum at $450{ }^{\circ} \mathrm{C}$. Vertical lines correspond to calculated wave numbers for (1) molecular adsorption of water at $\mathrm{Ti}_{8} \mathrm{O}_{28} \mathrm{H}_{24}$ (red dotted lines), and (2) dissociative adsorption of water at $\mathrm{Ti}_{8} \mathrm{O}_{28} \mathrm{H}_{24}$ (green dashed lines).

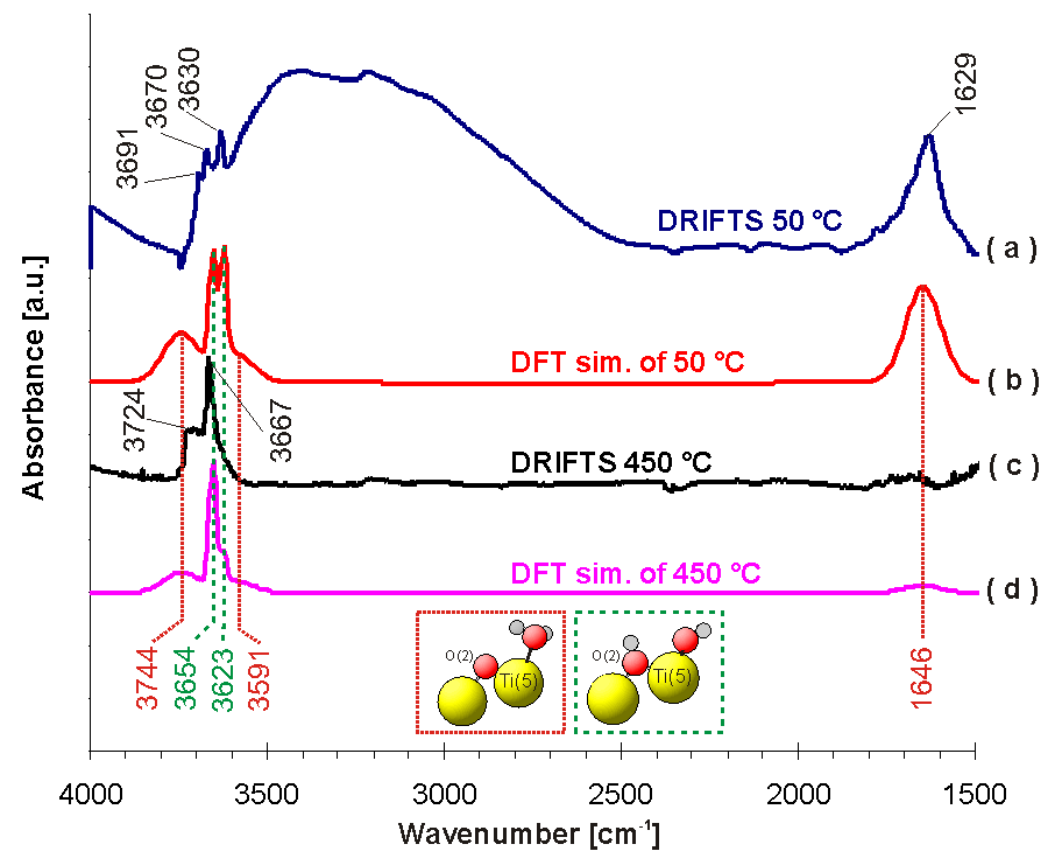

\subsection{Isocyanic Acid Behaviour at Different Catalysts}

Isocyanic acid (HNCO) is formed from the thermolysis of urea, which is used as an ammonia precursor compound in the selective catalytic reduction of nitrogen oxides in diesel engines. HNCO itself hydrolyses to ammonia and carbon dioxide. The hydrolysis of isocyanic acid is possible over a variety of metal oxides, among which $\mathrm{TiO}_{2}$ and $\mathrm{Al}_{2} \mathrm{O}_{3}$ were selected to study the mechanism both theoretically and with in situ DRIFT investigations.

The first calculation has been made for the isocyanic acid molecule in the gas phase in order to validate the electronic parameters' accuracy. A comparison between results from DFT codes (StoBe and Gaussian98) and experimentally derived vibrational frequencies of pure HNCO are shown in Table 3. Very good agreement of theoretical frequencies and experimental data of Ranier et al. [31] has been found for the calculations with the StoBe code.

As a next step the adsorption of isocyanic acid $\mathrm{TiO}_{2}$ and $\mathrm{Al}_{2} \mathrm{O}_{3}$ has been investigated. The calculations revealed that dissociative as well as molecular adsorption of HNCO is possible and energetically feasible on both the $\mathrm{TiO}_{2}(101)$ [6,7] and the $\mathrm{Al}_{2} \mathrm{O}_{3}(100)$ surface [8,32,33]. Figure 5 shows adsorption energies as well as geometric structures of $\mathrm{HNCO}$ interacting with different sites of $\mathrm{TiO}_{2}(101)$ and $\mathrm{Al}_{2} \mathrm{O}_{3}(100)$. These surfaces are represented by $\mathrm{Ti}_{8} \mathrm{O}_{28} \mathrm{H}_{24}$ and $\mathrm{Al}_{11} \mathrm{O}_{30} \mathrm{H}_{27}$ clusters, 
respectively. The $\mathrm{HNCO}$ or $-\mathrm{NCO}$ groups are stabilized at the $\mathrm{M}(5)$ centres of these clusters. In case of dissociative adsorption on $\mathrm{Al}_{2} \mathrm{O}_{3}$, hydrogen is bound to the $\mathrm{O}(3)$ oxygen side in parallel to the adsorption of water (see paragraph 3.2). The HNCO molecule is bound to the $\mathrm{M}(5)$ centres with stabilization energies of $-0.40 \mathrm{eV}$ and $-0.72 \mathrm{eV}$ for $\mathrm{TiO}_{2}$ and $\mathrm{Al}_{2} \mathrm{O}_{3}$, respectively. The energies for dissociative adsorption are $-0.91 \mathrm{eV}$ and $-1.11 \mathrm{eV}$ for $\mathrm{TiO}_{2}$ and $\mathrm{Al}_{2} \mathrm{O}_{3}$, respectively. As shown in Figure 3, water adsorbs dissociatively with an adsorption energy of $\mathrm{E}_{\mathrm{ad}}=-0.84 \mathrm{eV}\left(\mathrm{TiO}_{2}\right)$ and $-1.06 \mathrm{eV}$ $\left(\mathrm{Al}_{2} \mathrm{O}_{3}\right)$. This means that dissociative adsorption of isocyanic acid is favourable, and competitive with respect to water adsorption.

Table 3. Comparison of vibrational frequencies obtained from theoretical (DFT) codes: StoBe and Gaussian98 with experimental and literature data for pure HNCO.

\begin{tabular}{|c|c|c|c|c|c|}
\hline \multirow{2}{*}{} & \multicolumn{3}{|c|}{ DFT } & \multirow{2}{*}{$\begin{array}{c}\text { Experiment } \\
\text { StoBe }\end{array}$} & $\begin{array}{c}\text { Theory- } \\
\text { (PBE) }\end{array}$ \\
\cline { 2 - 4 } & haussian98 & & (B3LYP) \\
\cline { 2 - 4 } Frequencies $\left[\mathbf{c m}^{-1}\right]$ & unhar. & har. & & har. \\
\hline$v(\mathrm{NH})$ & 3,578 & 3,536 & 3,678 & 3,511 & 3,791 \\
\hline$v_{\text {as }}(\mathrm{NCO})$ & 2,259 & 2,259 & 2,356 & $\mathbf{2 , 2 5 9}$ & 2,366 \\
\hline$v_{\mathrm{s}}(\mathrm{NCO})$ & 1,269 & 1,267 & 1,338 & $\mathbf{1 , 3 1 6}$ & 1,310 \\
\hline$\delta(\mathrm{HNC})$ & 833 & 833 & 780 & $\mathbf{7 7 0}$ & 794 \\
\hline$\pi(\mathrm{NCO})$ & 583 & 583 & 611 & $\mathbf{6 9 7}$ & 610 \\
\hline$\delta(\mathrm{NCO})$ & 547 & 547 & 562 & $\mathbf{5 7 3}$ & 559 \\
\hline
\end{tabular}

* Raunier et al. [31]; har.-harmonic approximation; unhar.-unharmonic approximation.

Figure 5. Geometric structure of isocyanic acid at $\mathrm{TiO}_{2}$ and $\mathrm{Al}_{2} \mathrm{O}_{3}$. Colour code: (oxygenred, nitrogen-blue, carbon-black, hydrogen-light gray, titanium-yellow, aluminium-dark gray).

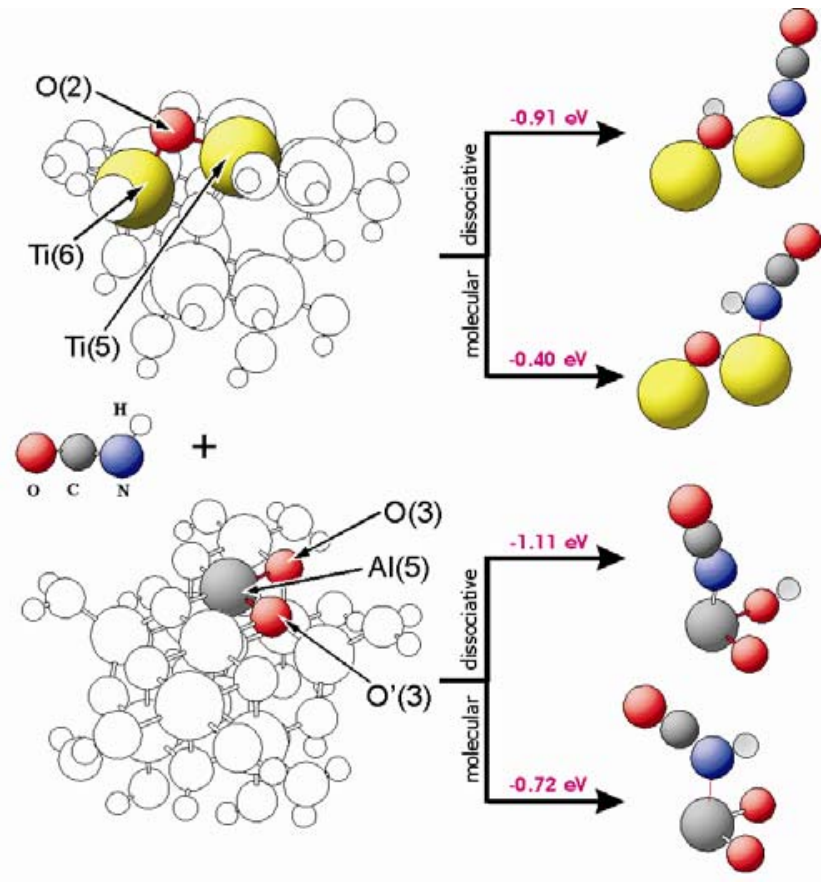


Due to the fact that the catalysts are working under humid conditions, any investigation of the reaction mechanism of the $\mathrm{HNCO}$ hydrolysis has to consider co-adsorption of $\mathrm{HNCO}$ and $\mathrm{H}_{2} \mathrm{O}$ on the catalyst surface. This approach comprises the competitive adsorption of water and isocyanic acid, as well as the interaction of water with isocyanic acid adsorbates. It also requires the presence of free neighboured five-fold coordinated metal sites.

Figure 6. The energy diagram for the hydrolysis of $\mathrm{HNCO}$ on $\mathrm{TiO}_{2}(101)$ (blue levels) and $\gamma-\mathrm{Al}_{2} \mathrm{O}_{3}$ (100) (red levels). Colour code: (oxygen-red, nitrogen-blue, carbon-black, hydrogen-light gray, titanium-yellow, aluminium-dark gray). At the picture only centers active in adsorption are shown. (a) Cluster $+\mathrm{HNCO}$ reference level. (b) Dissociative adsorption of $\mathrm{HNCO}$ on the catalyst. (c) Water attack on the NCO group at the M(5) site and formation of surface carbamic acid (NHCOOH). (d) Transfer of the carboxyl $\mathrm{H}$ to the $\mathrm{NH}$ group. (e) Formation of adsorbed carbamate $\left(\mathrm{NH}_{2} \mathrm{CO}_{2}\right)$ at the $\mathrm{M}(5)$ site. (f) $\mathrm{CO}_{2}$ separation from the $\mathrm{NH}_{2}$ surface group. (g) $\mathrm{CO}_{2}$ desorption and stabilization of the $\mathrm{NH}_{2}$ group at $\mathrm{M}(5)$. (h) Migration of the $\mathrm{H}$ from adsorbed water to $\mathrm{NH}_{2}$. (i) $\mathrm{NH}_{3}$ at the $\mathrm{M}(5)$ site.

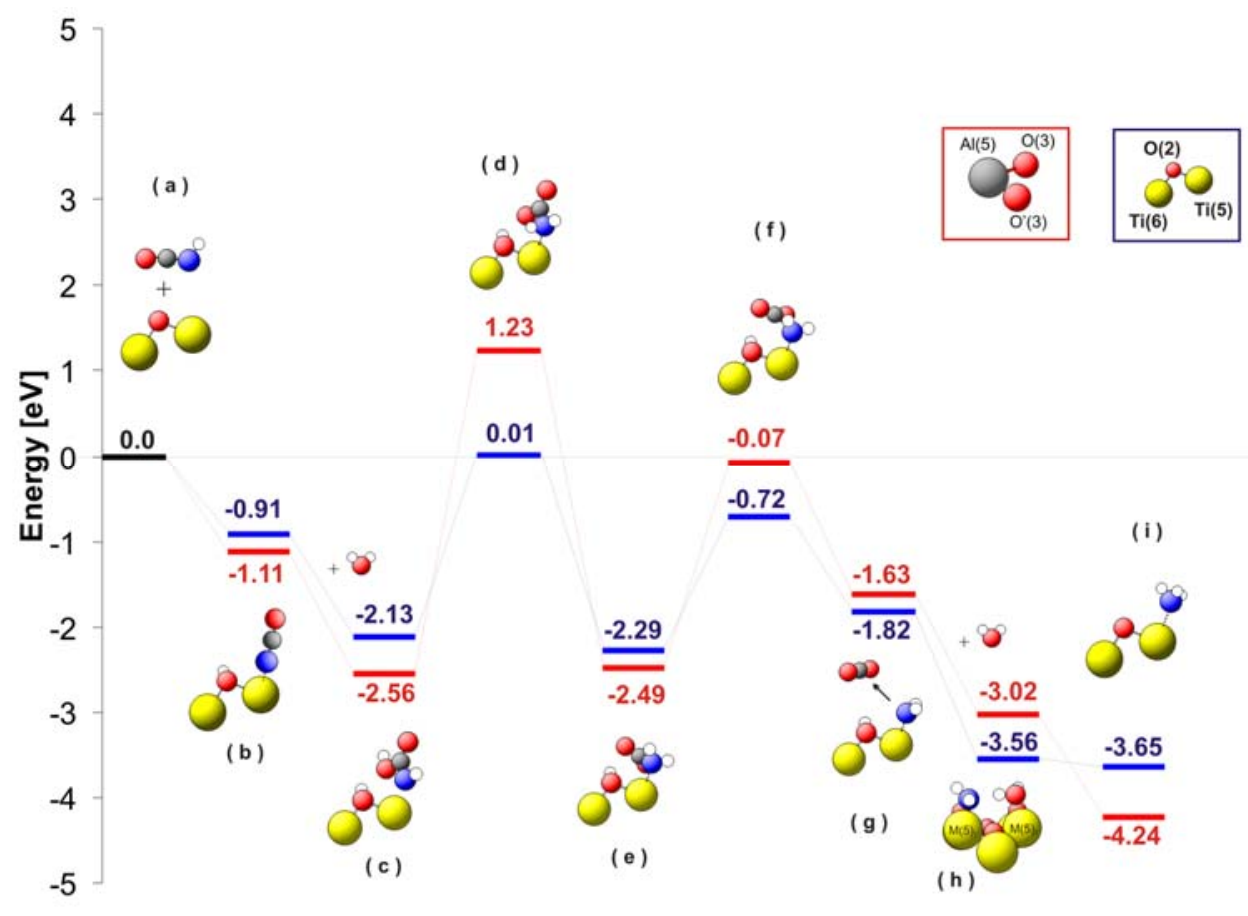

Figure 6 shows a comparison of the energy levels for the different intermediates observed during hydrolysis of isocyanic acid. The first important step of the reaction mechanism is dissociative adsorption of HNCO (see Figure 6b). After stabilization at the surface, $-\mathrm{NCO}$ groups are attacked by a water molecule. As consequence of this water attack, a carbamic acid complex is formed (-NHCOOH) without energy barrier. The carbamic acid is strongly adsorbed on the surface with an energy of $-2.13 \mathrm{eV}$ for $\mathrm{TiO}_{2}$ and $-2.56 \mathrm{eV}$ for $\mathrm{Al}_{2} \mathrm{O}_{3}$. Thereupon, the carbamic acid changes its conformation in a highly endothermic process transferring hydrogen from carbonylic oxygen to the nitrogen atom (see Figure 6d). Consequently, a carbamate complex $\left(-\mathrm{NH}_{2} \mathrm{CO}_{2}\right)$ is formed at the surface (Figure 6e). This 
carbamate complex decarboxylates (Figure $6 \mathrm{~g}$ ) and the $\mathrm{NH}_{2}$ group remains at the $\mathrm{M}(5)$ site. The formation of ammonia requires an additional hydrogen atom, which can be obtained from a water molecule adsorbed on a neighbouring $\mathrm{M}(5)$ site. This hydrogen transfer from a second water molecule is facilitated by the very low energy level of the system after the adsorption of water $(-3.56 \mathrm{eV}$ for $\mathrm{TiO}_{2}$ and $-3.02 \mathrm{eV}$ for $\mathrm{Al}_{2} \mathrm{O}_{3}$; Figure 6h). The $\mathrm{NH}_{3}$ is finally released from the catalyst surface enriching the catalyst surface with $\mathrm{OH}$ groups. This is in agreement with the in situ DRIFTS experiments described below, since strong $\mathrm{OH} /$ water vibrations are visible after reaction always. As an additional proof for the accuracy of our reaction mechanism a comparison of the theoretical vibrational spectra of the reaction intermediates of the $\mathrm{HNCO}$ adsorption on $\mathrm{TiO}_{2}$ and $\mathrm{Al}_{2} \mathrm{O}_{3}$ with the in situ DRIFT spectrum for $\mathrm{TiO}_{2}$ has been performed. An example of these spectra is shown in Figure 7 for the $\mathrm{TiO}_{2}$ catalyst.

Figure 7. Theoretical vibrational IR spectra and experimental DRIFT spectrum of HNCO adsorption $(70 \mathrm{ppm})$ on $\mathrm{TiO}_{2}$ at $150{ }^{\circ} \mathrm{C}$ (experimental procedure: $15 \mathrm{~min} \mathrm{HNCO}$ adsorption followed by $15 \mathrm{~min}$ nitrogen purging). The insets show enlarged areas of certain areas of the theoretical spectrum and relate the origin of the peaks to the individual compounds (see colour code). For that list of vibrational frequencies $\left(\mathrm{cm}^{-1}\right)$ of individual surface intermediates see also Table 4.

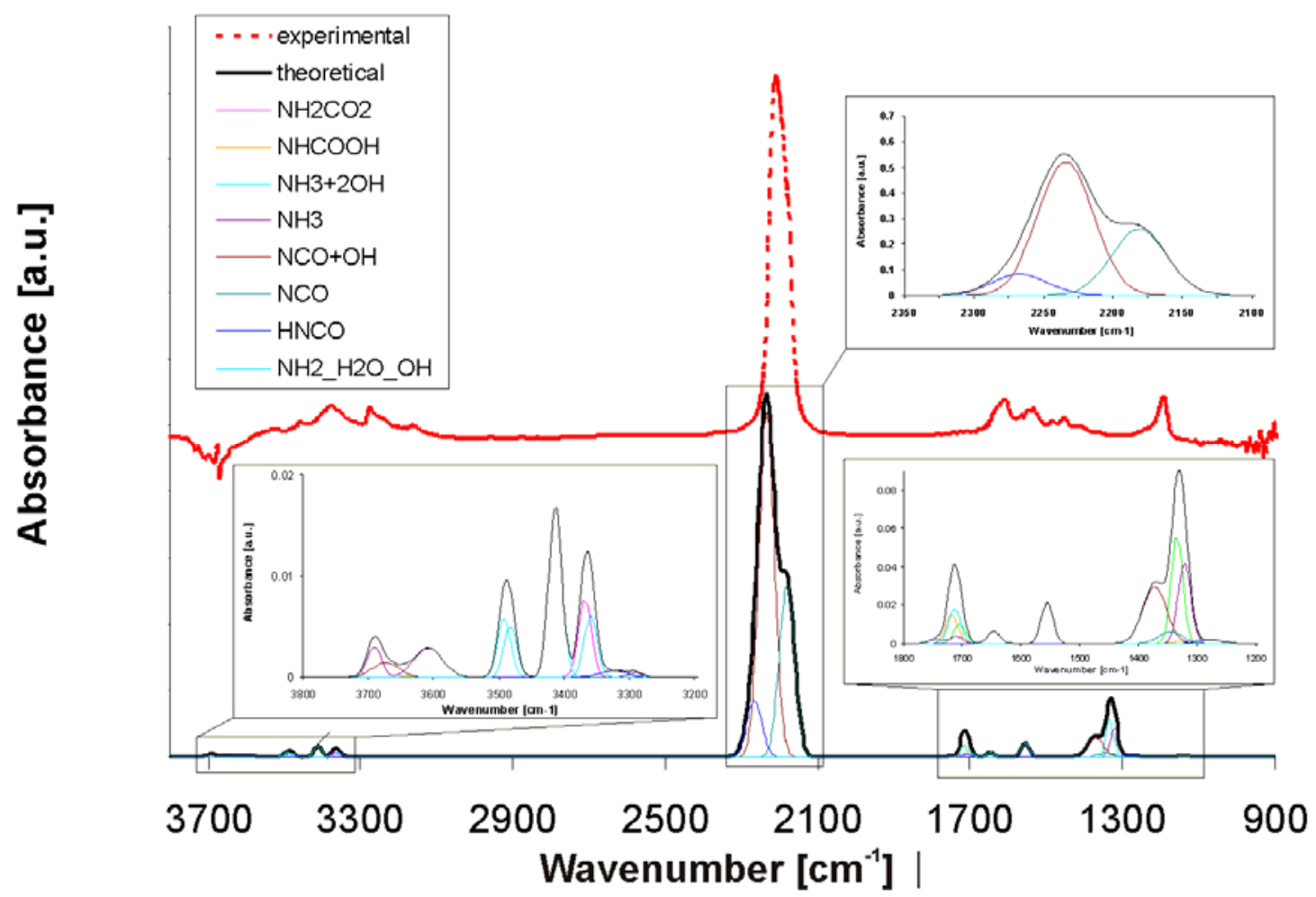

In the following, we give a brief introduction how to obtain theoretical IR spectra. The calculations of the vibrational frequencies were performed using harmonic approximations with additional anharmonicity fit as discussed in Chapter 2 [18]. The vibrational spectrum of the individual adsorbates includes all vibrations and their characteristic intensities (see Table 4). The frequency of a vibration is based on mechanical properties (anharmonically oscillating atomic masses) whereas its intensity is a 
function of the change in dipole moment [34]. The amplitude of a peak in a vibrational spectrum is proportional to the square of the first derivative of the dipole momentum of the molecule with respect to one of the normal-mode vibrational coordinates (a combination of nuclear displacement coordinates of the equilibrium geometry).

Therefore in our case the intensity of a certain vibrational mode of an adsorbate is a function of the square of its dipole momentum. The final spectrum of an individual adsorbate has been described by Gaussian line shapes function with the same line width $\left(50 \mathrm{~cm}^{-1}\right)$ in order to obtain realistic peak shapes.

A complete theoretical vibrational spectrum was obtained by convolution of the vibrational spectra of all individual adsorbates determined to be present in the considered reaction path under the reaction condition applied (e.g., water or hydroxyl groups adsorbed at neighboured metal centres), applying Gaussian line-shapes. The wavenumbers are reported as obtained from the calculations. The adsorption of isocyanic species with different surroundings has been considered with presence or absence of water, for example $\mathrm{NCO}$ and $\mathrm{NCO}_{\mathrm{aq}}$, see Table 4. Due to the fact that in DRIFT spectroscopy the measured intensity of a certain vibration is a function of the number of adsorbed molecules, the theoretical spectrum of the individual adsorbates/intermediates have to be scaled separately to simulate the different populations of the individual adsorbates. The aim is to obtain the best possible fit to the experimental data.

Table 4. The $\mathrm{HNCO}$ adsorption at $\mathrm{TiO}_{2}(101)$ and $\gamma-\mathrm{Al}_{2} \mathrm{O}_{3}$ (100): theoretical vibrational frequencies $\left(\mathrm{cm}^{-1}\right)$ of individual surface intermediates.

\begin{tabular}{|c|c|c|c|c|}
\hline & \multicolumn{2}{|c|}{$\mathbf{T i O}_{\mathbf{2}}$} & \multicolumn{2}{c|}{$\mathbf{A l}_{\mathbf{2}} \mathbf{O}_{3}$} \\
\hline $\mathbf{v}$ (NCO) & $\mathbf{S y m}$. & Asym. & Sym. & Asym. \\
\hline $\mathrm{HNCO}$ & 1,279 & 2,266 & 1,263 & 2,264 \\
\hline $\mathrm{NCO}_{\mathrm{aq}}$ & 1,351 & 2,234 & 1,342 & 2,274 \\
\hline $\mathrm{NCO}$ & 1,345 & 2,181 & 1,364 & 2,293 \\
\hline $\mathbf{v}$ (N-H/H-N-H) & Sym. & Asym. & Sym. & Asym. \\
\hline $\mathrm{NHCOOH}$ & 3,462 & - & 3,280 & - \\
\hline $\mathrm{NH}_{2} \mathrm{CO}_{2}$ & 3,346 & 3,482 & 3,364 & 3,488 \\
\hline $\mathrm{NH}_{2 \mathrm{aq}}$ & $2,905 / 3,349$ & 3,466 & $3,406 / 3,425$ & 3,533 \\
\hline $\mathrm{NH}_{3 \mathrm{aq}}$ & $2,955 / 3,381$ & 3,492 & $3,068 / 3,394$ & 3,484 \\
\hline
\end{tabular}

The detailed theoretical spectrum comprising all individual adsorbates/intermediates, which are considered for the hydrolysis of isocyanic acid, is shown in Figure 7. The red curve shows the experimental DRIFT spectrum of the system $\mathrm{HNCO} / \mathrm{TiO}_{2}$ without water at $150{ }^{\circ} \mathrm{C}$. A strong band at $2,209 \mathrm{~cm}^{-1}$ together with less intense bands in the range 3,524-3,163 and 1,619-1,190 $\mathrm{cm}^{-1}$ are visible. The strong band at $2,209 \mathrm{~cm}^{-1}$ is assigned to the asymmetric stretching vibrations of -NCO groups adsorbed on the surface. From our theoretical studies we found that the main contribution to this band comes from dissociatively adsorbed isocyanic acid, stabilized on $\mathrm{M}(5)$ centres, evoking the vibration at $2,234 \mathrm{~cm}^{-1}$ in the neighbourhood of strong $\mathrm{OH}$ groups (see brown individual curve) and the vibration at $2,181 \mathrm{~cm}^{-1}$ in the absence of $\mathrm{OH}$ groups (light blue individual curve). However, small amounts of 
HNCO adsorbed in molecular form can be found at 2,266 $\mathrm{cm}^{-1}$ (light blue individual curve), which is very close to the vibration of gaseous $\operatorname{HNCO}\left(2,259 \mathrm{~cm}^{-1}\right)$.

In the case of the $\mathrm{Al}_{2} \mathrm{O}_{3}$ catalyst the theoretically predicted vibrations of the $-\mathrm{NCO}$ groups are at $2,274 \mathrm{~cm}^{-1}$ in case of dissociative adsorption and at 2,264 $\mathrm{cm}^{-1}$ in case of molecularly adsorbed HNCO. These vibrations are also in good agreement with experimental data presented recently by Ozensoy et al. [22], who recorded TD-FTIR spectra at $120{ }^{\circ} \mathrm{C}$ and who found a band at $2,254 \mathrm{~cm}^{-1}$. The calculated vibrations of $\mathrm{NCO}_{\mathrm{aq}}$ and $\mathrm{HNCO}$ are very close to each other suggesting that on $\mathrm{Al}_{2} \mathrm{O}_{3}$ rather isocyanic acid in molecular form can be found. This is in good agreement with the higher adsorption energy of molecular $\mathrm{HNCO}$ on $\mathrm{Al}_{2} \mathrm{O}_{3}(-0.72 \mathrm{eV})$ compared to $\mathrm{TiO}_{2}(-0.40 \mathrm{eV})$ (see Figure 5).

The theoretical bands below $1,800 \mathrm{~cm}^{-1}$ and above $3,000 \mathrm{~cm}^{-1}$ in Figure 7 have a similar shape as in the experimental $\mathrm{TiO}_{2}$ spectrum, but they are shifted to higher frequencies. This could be due to differences in mass, bond strength or other effects. The low frequency bands in the $1,200-1,800 \mathrm{~cm}^{-1}$ range in the calculated spectrum correspond to the bending vibrations of $\mathrm{NH}_{2}$ or $\mathrm{NH}_{3}$ as well as $\mathrm{NH}_{2} \mathrm{CO}_{2}$ and $\mathrm{NHCOOH}$ and the symmetric stretching vibrations of $\mathrm{NCO}$ influenced by water. The high frequency bands in the $3,000-3,500 \mathrm{~cm}^{-1}$ range are the sum of the N-H stretching vibrations of the individual adsorbates influenced by water.

The intermediate complexes, such as $-\mathrm{NCO}$ or carbamic acid, have higher stabilisation energies at the $\mathrm{Al}_{2} \mathrm{O}_{3}$ surface, which simply means that it will be more difficult to convert them into the following surface complexes. This finding is in agreement with our experimental result that $\mathrm{Al}_{2} \mathrm{O}_{3}$ has a lower activity than $\mathrm{TiO}_{2}$ for the $\mathrm{HNCO}$ hydrolysis.

\subsection{Theoretical Modelling of Binding Energies of Different Elements}

As the last example we have selected the investigation of the deactivation of $\mathrm{V}_{2} \mathrm{O}_{5} / \mathrm{WO}_{3}-\mathrm{TiO}_{2} \mathrm{SCR}$ catalysts by lubrication oil additives, which is of high significance for the $\mathrm{NO}_{\mathrm{x}}$ reduction in diesel vehicles. In this project the influence of dopant metals on the binding energies of oxygen in a $\mathrm{V}-\mathrm{W}-\mathrm{Ti}-\mathrm{O}$ catalyst was investigated theoretically by modelling the doping of $\mathrm{VO}_{\mathrm{x}}$ [9]. In this type of catalyst the active face are two dimensionally spreaded $\mathrm{VO}_{\mathrm{x}}$ surface polymers and consequently, we limited our study on the influence of the metals on the active face only.

The two dimensional $\mathrm{VO}_{\mathrm{x}}$ surface species were described by clusters, which consist of six vanadium atoms, $\mathrm{V}_{6} \mathrm{O}_{20} \mathrm{H}_{10}$, as shown as inset in Figure 8. The $\mathrm{V}_{6} \mathrm{O}_{20} \mathrm{H}_{10}$ cluster represents all possible single-, double- and three-fold coordinated oxygen centres and five-fold coordinated vanadium centres on a orthorhombic $\mathrm{V}_{2} \mathrm{O}_{5}(010)$ surface as well as the particular hole between the vanadyl-oxygen centres, where dopant metals are especially stabilized. Two dopant metals were tested, $\mathrm{K}$ and $\mathrm{Ca}$, which were positioned in the energetically favourable hole position between vanadyl oxygen centres, following theoretical studies of Witko et al. [36].

XPS analyses of the individual components of the V-W-Ti-O catalyst, mainly $\mathrm{V}_{2} \mathrm{O}_{5}, \mathrm{TiO}_{2}, \mathrm{WO}_{3}$ and $\mathrm{TiO}_{2}-\mathrm{WO}_{3}$, was carried out to obtain information about binding energies and full-width-at-halfmaximum data for the oxygen O1s region. The spectra were measured in our VG ESCALAB 220i XL set-up using the $\mathrm{Mg}$ X-ray source applying $15 \mathrm{kV}$ and $30 \mathrm{~mA}$ in large area geometry. For a more detailed description see ref. [9]. Sample charging was in the order of $10 \mathrm{eV}$. The binding energy (BE) 
scale was adjusted by setting the main $\mathrm{C} 1 \mathrm{~s}$ peak to $284.5 \mathrm{eV}$. The spectra were deconvoluted applying Gaussian-Lorentzian line-shapes and a Shirley-type background.

Figure 8. $\mathrm{XP}$ spectrum $(\mathrm{Mg} \mathrm{K} \alpha)$ and deconvolution of the $\mathrm{O} 1 \mathrm{~s} \mathrm{BE}$ region for the pure $(\mathrm{V}-\mathrm{W}-\mathrm{Ti}-\mathrm{O})$ and Ca-poisoned $(\mathrm{V}-\mathrm{W}-\mathrm{Ti}-\mathrm{O}+\mathrm{Ca})$ samples. Vertical lines refer to the calculated BE's. In upper left corner the $\mathrm{V}_{6} \mathrm{O}_{20} \mathrm{H}_{10}$ cluster is shown with the characteristic active centres.

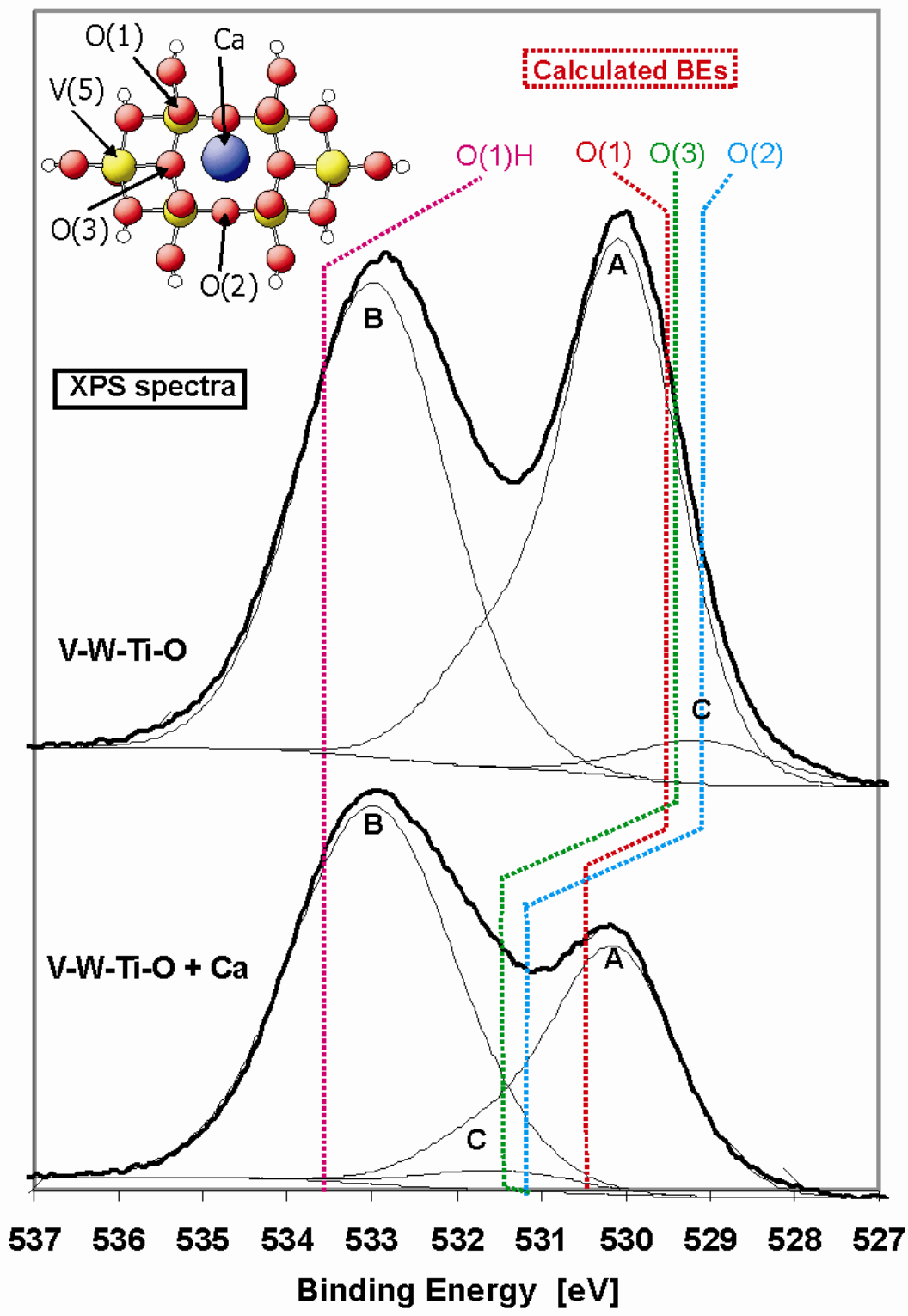

As background for calculations of theoretical binding energies the Koopmans theorem can be taken. If the ground state of the system is considered and assuming the remaining electrons as being inert, then the binding energy of a particular electron is equal to the negative energy of the orbital eigenvalue: $E_{b}=-\varepsilon_{b}$. However, especially valence electrons respond due to the removal of a photoelectron, and also their relaxation and correlation energy must be included in the binding energy calculations. The relaxation and correlation energy can be included by calculating the binding energy 
as difference of the total energy between the ground state system $\left(\mathrm{E}_{\text {tot }}^{\text {Ground }}\right)$ and the final state after emission of a particular electron, and the electron hole in the system $\left(\mathrm{E}_{\text {tot }}^{\text {Final }}\right)$ :

$$
\mathrm{E}_{\mathrm{b}}=-\varepsilon_{\mathrm{b}}-\mathrm{E}_{\text {tot }}^{\text {Ground }}+\mathrm{E}_{\text {tot }}^{\text {Final }}+\mathrm{E}_{\text {corr }}
$$

This definition is more accurate then Koopmans theorem and guarantees that relaxation of the remaining electrons is included.

XPS binding energies of the $\mathrm{O} 1 \mathrm{~s}$ region of the $\mathrm{V}_{6} \mathrm{O}_{20} \mathrm{H}_{10}$ cluster were calculated as the total energy difference between ground state and the core ionized state [37]. The theoretically obtained binding energies were shifted by i) subtracting the sample work-function, and by ii) adding a relativistic correction $(+0.33 \mathrm{eV}$ for $\mathrm{O})$ [38]. The effective core potentials (ECP) were used for all other oxygen atoms to localize the core hole on the particular oxygen centres, $\mathrm{O}(1), \mathrm{O}(2)$ and $\mathrm{O}(3)$.

In Figure 8 the $\mathrm{O}$ 1s XP spectrum of the pure and metal-doped V-W-Ti-O catalyst is presented. The spectra exhibit a two-peak structure at about $530 \mathrm{eV}$ and $533 \mathrm{eV}$, which can be correlated with a $\mathrm{TiO}_{2}-\mathrm{WO}_{3}$ (peak A) compound and hydroxyl groups (peak B), respectively. For the deconvolution of the measured spectra, reference samples of single and mixed metal oxides were used $\left(\mathrm{TiO}_{2}, \mathrm{WO}_{3}\right.$, $\mathrm{V}_{2} \mathrm{O}_{5}$ and $\mathrm{TiO}_{2}-\mathrm{WO}_{3}$, see Table 5). Peak A (529.8 eV) and peak $\mathrm{B}(533.0 \mathrm{eV})$ were kept fixed during the fitting. The derived binding energies are listed in Table 5. The asymmetry in peak A is caused by oxygen in $\mathrm{WO}_{3}$ that has a higher binding energy $(531.7 \mathrm{eV})$ and therefore $\mathrm{TiO}_{2}-\mathrm{WO}_{3}$ has been chosen as most suitable reference sample for this peak. Additionally, a small peak at about $529 \mathrm{eV}$ can be distinguished (peak C, see Figure 8, V-W-Ti-O sample), which is likely connected with $\mathrm{V}_{2} \mathrm{O}_{5}$. During deconvolution the ratio between the content of $\mathrm{V}_{2} \mathrm{O}_{5}$ and $\mathrm{TiO}_{2}$ in the catalyst has been taken into account. In the upper spectrum of the V-W-Ti-O catalyst, the peak at lower BE corresponds quite well with our theoretical predictions of the binding energies of the different surface oxygen groups (see Table 5 and Figure 8) of pure $\mathrm{V}_{2} \mathrm{O}_{5}$. The binding energies of oxygen on a pure $\mathrm{V}_{2} \mathrm{O}_{5}(010)$ surface are localized at about $529.3 \mathrm{eV}$, which is exactly the position of peak $\mathrm{C}$ in case of the V-W-Ti-O sample.

The terminal oxygen, $\mathrm{O}(1)$, is most important for the SCR reaction [36], for which the possible formation of $\mathrm{OH}$ group was considered in the calculation of the oxygen binding energy in $\mathrm{O}(1)$. The binding energy of terminal oxygen of Brønsted acidic $\mathrm{V}-\mathrm{OH}$ site is equal $533.5 \mathrm{eV}$, which corresponds well with the second prominent peak (BE about $533 \mathrm{eV}$ ). However, it has to be noted that Brønsted acidic sites could also come from other components of the catalyst, mainly $\mathrm{TiO}_{2}$.

Doping of the V-W-Ti-O with Ca leads to a decrease of the O1s signal located at the lower binding energy. Additionally, the peak labelled as "B" starts to be more asymmetric towards the lower binding energy range. We assign this asymmetry to the appearance of a third peak " $\mathrm{C}$ " at an energy position between 531-532 eV (see Figure 8, V-W-Ti-O + Ca), which is in agreement with a theoretically determined binding energy shift after Ca-doping (see Table 5). The theoretically determined binding energies of oxygen at the metal doped $\mathrm{V}_{2} \mathrm{O}_{5}(010)$ surface are also shifted to higher energies (centred at $530.9 \mathrm{eV}$ ). However, the predicted shift of the oxygen binding energies was somewhat lower than the experimental value. A reason for this may be the additional shift of $\mathrm{O}$ binding energies in real $\mathrm{V}-\mathrm{W}-\mathrm{Ti}-\mathrm{O}$ system compared to pure $\mathrm{V}_{2} \mathrm{O}_{5}$. However, the trend of the O1s peak shift is similar and offers a proper explanation of the role of the metal-dopant. Changes in the O1s signal after doping is connected with the formation of strong bonds between surface oxygen centres and the metal-dopant as well as an electron transfer from the dopant to the oxygen centre. Consequently, the oxygen becomes 
increasingly negatively charged and therefore exhibits a higher binding energy. Due to the charge transfer and a coupling with additional elements, the surface oxygen is supposed to be less reactive than in pure V-W-Ti-O catalyst.

Table 5. DFT-obtained atomic charges, distances $(\AA)$ and bond orders (Mayer bond analysis) of the pure and Ca-doped $\mathrm{V}_{6} \mathrm{O}_{20} \mathrm{H}_{10}$ cluster modelling the $\mathrm{V}_{2} \mathrm{O}_{5}(010)$ surface.

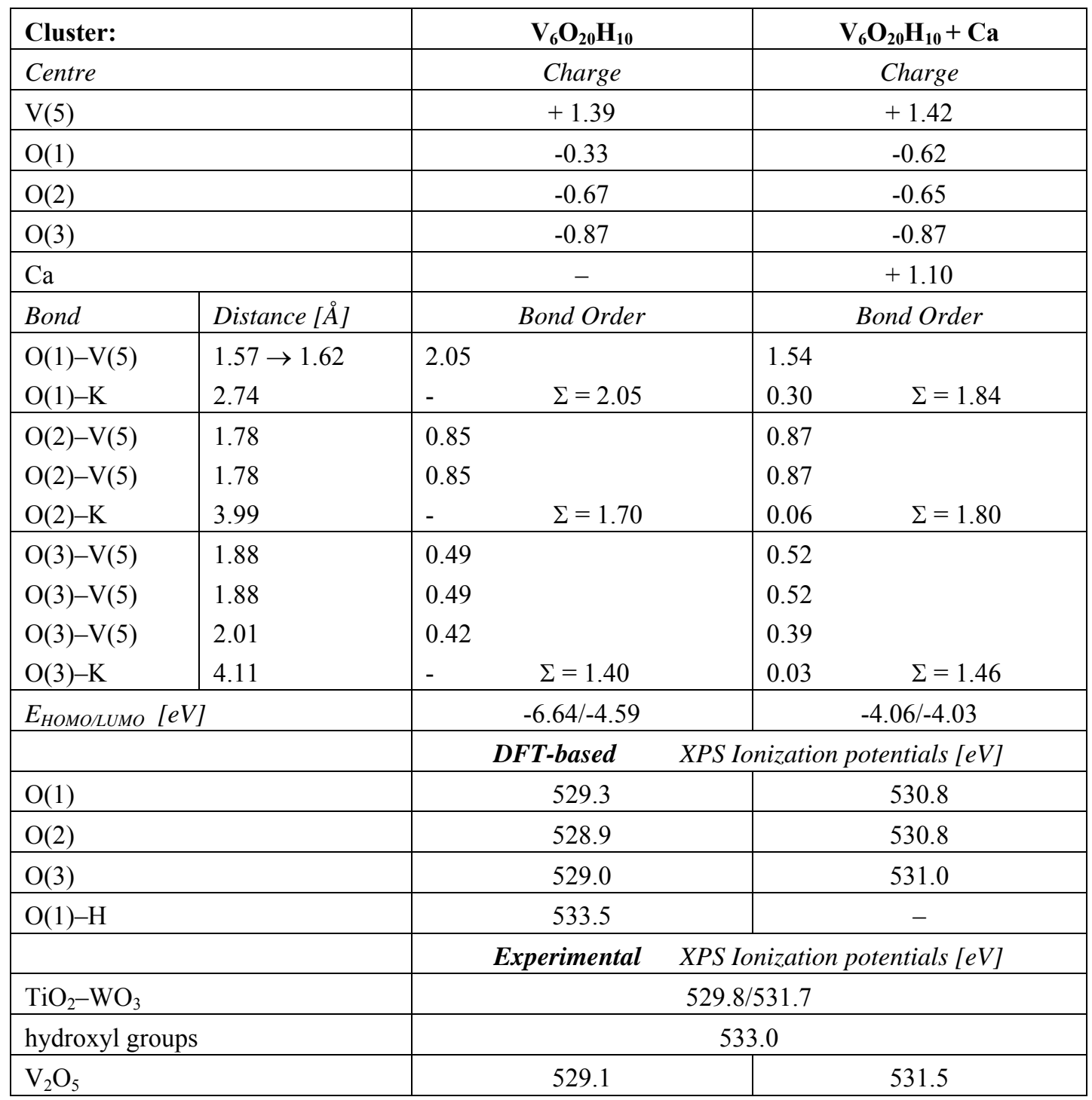

\section{Conclusions}

After many years of DFT investigations, the level of theoretical insight into the electronic structures, geometries, stabilities and adsorption properties of model catalysts is now reaching a level that the investigation of more complex catalytical systems becomes possible with this method. In our research activities we try to build a bridge between applied industrial catalysts and model systems at an atomic level by using a combination of experimental and theoretical methods. Following this approach, the methodology for the investigation of catalytic systems has been discussed on the basis of the following examples: (i) investigations and modeling of metal-support interfaces, (ii) modeling of 
reaction mechanisms by comparison of theoretical and experimental DRIFT spectra, (iii) investigation of catalyst deactivation by combination of experimental and theoretical XPS spectra.

The shown examples clearly demonstrated that state-of-the-art cluster calculations are well suited for studying model as well industrially relevant catalysts, since always a good fit of theoretical calculations and experimental data (DRIFT, XPS spectra) was reached. Insight was provided into the catalyst structures and their functionality in the investigated reactions. In the first example, we could successfully describe the structure and deactivation mechanism of an industrial $\mathrm{Ni} / \mathrm{Al}_{2} \mathrm{O}_{3}$ catalyst by a cluster model. Secondly, we resolved the reaction mechanism of the isocyanic acid hydrolysis over $\mathrm{TiO}_{2}$ and successfully interpreted the corresponding DRIFT spectra and, thirdly, cluster model calculations helped us to deconvolute XPS spectra and to understand deactivation phenomena of vanadia-SCR catalysts. The results obtained so far on the hydrolysis of isocyanic acid indicate that even a computational screening might be feasible for identification of better catalytic materials for this reaction.

In our opinion, cluster models are especially suited for the description and prediction of materials, in which small clusters are catalytically active. Another important advantage of cluster models is the possibility to study the interactions of adsorbates with an ideal catalyst surface as well as with single defects (e.g., vacancies) at low surface coverages.

However, several challenges still remain on the long road of a complete understanding of realworld catalysts: (i) a more detailed explanation of imperfections, e.g., defects, steps, and their effects on the reactivity of catalysts is required, (ii) a more detailed description of complex systems is needed, where different material are either the support or the supported phase, and (iii) it is necessary to improve the models for theoretical spectra of complex systems. It would be desirable to use both cluster and periodic cell models for the same problems in future and to compare the results in order better avoid errors coming from limitations of both approaches.

\section{Acknowledgements}

The DFT calculations were partially carried out with the UNIX and Linux farm at PSI. We would like to thank A. Foelske-Schmitz as well as F. Loviat for helping us with performing part of the XPS measurements. We would like to express our thanks to A. Wokaun for his helpful suggestions.

\section{References and Notes}

1. Czekaj, I.; Loviat, F.; Raimondi, F.; Wambach, J.; Biollaz, S.; Wokaun, A. Characterization of surface processes at Ni-based catalyst during the methanation of synthesis gas: X-ray photoelectron spectroscopy (XPS). Appl. Catal. A 2007, 329, 68-78.

2. Czekaj, I.; Loviat, F.; Wambach, J.; Wokaun, A. Nickel deposition on $\gamma-\mathrm{Al}_{2} \mathrm{O}_{3}$ : Modelling of metal particles behaviour at the support. Chimia 2009, 4, 193-196.

3. Loviat, F.; Czekaj, I.; Wambach, J.; Wokaun, A. Model studies of nickel deposition at $\gamma-\mathrm{Al}_{2} \mathrm{O}_{3}$ surface: Combination of experimental and theoretical results. Surf. Sci. 2009, 603, 2210-2217. 
4. Hermann, K.; Witko, M. Theory of physical and chemical behavior of transition metal oxides: Vanadium and molybdenum oxides. In The Chemical Physics of Solid Surfaces; Woodruff, D.P., Ed.; Elsevier Science: Amsterdam, the Netherlands, 2001; Volume 9, pp. 136-198.

5. Hejduk, P.; Witko, M.; Hermann, K. Electronic structure of unsaturated $\mathrm{V}_{2} \mathrm{O}_{5}(001)$ and (100) surfaces: Ab initio density functional theory studies. Top. Catal. 2009, 52, 1105-1115.

6. Czekaj, I.; Piazzesi, G.; Kröcher, O.; Wokaun, A. DFT modeling of the hydrolysis of isocyanic acid over the $\mathrm{TiO}_{2}$ anatase (101) surface: Adsorption of HNCO species. Surf. Sci. 2006, 600, 5158-5167.

7. Czekaj, I.; Kröcher, O.; Piazzesi, G. DFT calculations, DRIFT spectroscopy and kinetic studies on the hydrolysis of isocyanic acid on the $\mathrm{TiO}_{2}$-anatase (101) surface. J. Mol. Catal. A: Chem. 2008, 280, 68-80.

8. Czekaj, I.; Kröcher, O. Decomposition of urea in the SCR process: Combination of DFT calculations and experimental results on the catalytic hydrolysis of isocyanic acid (HNCO) on $\mathrm{TiO}_{2}$ and $\mathrm{Al}_{2} \mathrm{O}_{3}$. Top.Catal. 2009, in press.

9. Nicosia, D.; Czekaj, I.; Kröcher, O. Chemical deactivation of $\mathrm{V}_{2} \mathrm{O}_{5} / \mathrm{WO}_{3}-\mathrm{TiO}_{2}$ SCR catalysts by additives and impurities from fuels, lubrication oils, and urea solution-II. Characterization study of the effect of alkali and alkaline earth metals. Appl. Catal. B: Environ. 2008, 77, 228-236.

10. Hermann, K.; Pettersson, L.G.M. StoBe. A Modified Version of DFT-LCGTO Program Package deMon with Extensions. http://www.fhi-berlin.mpg.de/ hermann/StoBe/index.html (accessed January, 2008).

11. Perdew, J.P.; Burke, K.; Ernzerhof, M. Generalized gradient approximation made simple. Phys. Rev. Lett. 1996, 77, 3865-3868.

12. Hammer, B.; Hansen, L.B.; Norskov, J.K. Improved adsorption energetics within densityfunctional theory using revised Perdew-Burke-Ernzerhof functionals. Phys. Rev. B 1999, 59, 7413-7421.

13. Labanowski, J.K.; Anzelm, J.W. Density Functional Methods in Chemistry; Springer: New York, NY, USA, 1991.

14. Godbout, N.; Salahub, D.R.; Andzelm, J.; Wimmer, E. Optimization of Gaussian-type basis sets for local spin density functional calculations. Part I. Boron through neon, optimization technique and validation. Can. J. Chem. 1992, 70, 560-571.

15. Mulliken, R.S. Electronic population analysis on LCAO-MO molecular wave functions. J. Chem. Phys. 1955, 23, 1833-1844, 2338-2346.

16. Mayer, I. Charge, bond order and valence in the AB initio SCF theory. Chem. Phys. Lett. 1983, 97, 270-274.

17. Mayer, I. Bond orders and valences: Role of d-orbitals for hypervalent sulphur. J. Mol. Struct.: THEOCHEM 1987, 149, 81-89.

18. Friedrich, C. Geometrische, elektronische und vibronische Eigenschaften der reinen und defektbehafteten $\mathrm{V}_{2} \mathrm{O}_{5}(010)$-Oberfläche und deren Wechselwirkung mit Adsorbaten: Theoretische Untersuchungen. Ph.D. Thesis, FU Berlin, Berlin, Germany, 2004.

19. Marquez, A.M.; Sanz, J.F. Adsorption of Pd atoms on $\gamma$-A12O3: A density functional study of metal-support interactions. Appl. Surf. Sci. 2004, 238, 82-85. 
20. Valero, M.C.; Raybaud, P.; Sautet, P. Influence of the hydroxylation of $\gamma$-A12O3 surfaces on the stability and diffusion of single Pd atoms: A DFT study. J. Phys. Chem. B 2006, 110, 1759-1767.

21. Jacobs, J.P.; Lindfors, L.P.; Reintjes, J.G.H.; Jylhä, O.; Brongersma, H.H. The growth mechanism of nickel in the preparation of Ni/A12O3 catalysts studied by LEIS, XPS and catalytic activity. Catal. Lett. 1994, 25, 315-324.

22. Onal, I.; Soyer, S.; Senkan, S. Adsorption of water and ammonia on $\mathrm{TiO}_{2}$-anatase cluster models. Surf. Sci. 2006, 600, 2457-2469.

23. Vittadini, A.; Selloni, A.; Rotzinger, F.P.; Gratzel, M. Structure and energetics of water adsorbed at $\mathrm{TiO}_{2}$ anatase $\backslash(101 \backslash)$ and $\backslash(001 \backslash)$ surfaces. Phys. Rev. Lett. 1998, 81, 2954-2957.

24. Selloni, A.; Vittadini, A.; Grätzel, M. The adsorption of small molecules on the $\mathrm{TiO}_{2}$ anatase (101) surface by first-principles molecular dynamics. Surf. Sci. 1998, 402-404, 219-222.

25. Tilocca, A.; Selloni, A. Reaction pathway and free energy barrier for defect-induced water dissociation on the (101) surface of $\mathrm{TiO}_{2}$-anatase. J. Chem. Phys. 2003, 119, 7445-7450.

26. Handzlik, J.; Ogonowski, J.; Tokarz-Sobieraj, R. Dependence of metathesis activity of Momethylidene sites on their location on $\left(\begin{array}{lll}1 & 0 & 0\end{array}\right) \gamma$-A12O3-A theoretical study. Catal. Today 2005, 101, 163-173.

27. Digne, M.; Sautet, P.; Raybaud, P.; Euzen, P.; Toulhoat, H. Use of DFT to achieve a rational understanding of acid-basic properties of $\gamma$-alumina surfaces. J. Catalysis 2004, 226, 54-68.

28. Ionescu, A.; Allouche, A.; Aycard, J.P.; Rajzmann, M.; Hutschka, F. Study of gamma-alumina surface reactivity: Adsorption of water and hydrogen disulfide on octahedral aluminum sites. $J$. Phys. Chem. B 2002, 106, 9359-9366.

29. Piazzesi, G.; Kröcher, O.; Elsener, M.; Wokaun, A. Adsorption and hydrolysis of isocyanic acid on $\mathrm{TiO}_{2}$. Appl. Catal. B 2006, 65, 55-61.

30. Eisenberg, D.; Kauzmann, W. The Structure and Properties of Water; Oxford University Press: London, UK, 1969.

31. Raunier, S.; Chiavassa, T.; Allouche, A.; Marinelli, F.; Aycard, J.P. Thermal reactivity of HNCO with water ice: An infrared and theoretical study. Chem. Phys. 2003, 288, 197-210.

32. Cant, N.W.; Chambers, D.C.; Liu, I.O.Y. The reduction of NO by CO in the presence of water vapour on supported platinum catalysts: Formation of isocyanic acid (HNCO) and ammonia. Appl. Catal. B 2003, 46, 551-559.

33. Hauck, P.; Jentys, A.; Lercher, J.A. On the quantitative aspects of hydrolysis of isocyanic acid on TiO2. Catal. Today 2007, 127, 165-175.

34. Veszprémi, T.; Fehér, M. Quantum Chemistry: Fundamentals to Applications; Springer: New York, NY, USA, 1999.

35. Ozensoy, E.; Herling, D.; Szanyi, J. NOx reduction on a transition metal-free $\gamma$-Al2O3 catalyst using dimethylether (DME). Catal. Today 2008, 136, 46-54.

36. Witko, M.; Grybos, R.; Tokarz-Sobieraj, R. Heterogeneity of $\mathrm{V}_{2} \mathrm{O}_{5}(010)$ surfaces-The role of alkali metal dopants. Topics Catal. 2006, 38, 105-115.

37. Andersson, K. Structure, Bonding and Chemistry of Water and Hydroxyl on Transition Metal Surfaces. Ph.D. Thesis, University Stockholm, Sweden, 2006; pp. 1-62. 
38. Takahashi, O.; Pettersson, L.G.M. Functional dependence of core-excitation energies. J. Chem. Phys. 2004, 121, 10339-10345.

(C) 2009 by the authors; licensee Molecular Diversity Preservation International, Basel, Switzerland. This article is an open-access article distributed under the terms and conditions of the Creative Commons Attribution license (http://creativecommons.org/licenses/by/3.0/). 